\title{
Evaluation of radar reflectivity factor simulations of ice crystal populations from in situ observations for the retrieval of condensed water content in tropical mesoscale convective systems
}

\author{
Emmanuel Fontaine ${ }^{1,6}$, Delphine Leroy ${ }^{1}$, Alfons Schwarzenboeck ${ }^{1}$, Julien Delanoë ${ }^{2}$, Alain Protat ${ }^{3}$, Fabien Dezitter $^{4}$, \\ Alice Grandin ${ }^{4}$, John Walter Strapp ${ }^{5}$, and Lyle Edward Lilie ${ }^{5}$ \\ ${ }^{1}$ Université Clermont Auvergne, Laboratoire de Météorologie Physique, Aubière, France \\ ${ }^{2}$ Laboratoire Atmosphère, Milieux et Observations Spatiales, UVSQ, Guyancourt, France \\ ${ }^{3}$ Center for Australian Weather and Climate Research, Melbourne, Australia \\ ${ }^{4}$ Airbus, Toulouse, France \\ ${ }^{5}$ Met Analytics, Toronto, Canada \\ ${ }^{6}$ Department of Meteorology, University of Reading, Reading, UK
}

Correspondence to: Emmanuel Fontaine (e.r.j.fontaine@reading.ac.uk)

Received: 7 October 2016 - Discussion started: 24 October 2016

Revised: 29 March 2017 - Accepted: 10 April 2017 - Published: 13 June 2017

\begin{abstract}
This study presents the evaluation of a technique to estimate cloud condensed water content (CWC) in tropical convection from airborne cloud radar reflectivity factors at $94 \mathrm{GHz}$ and in situ measurements of particle size distributions (PSDs) and aspect ratios of ice crystal populations. The approach is to calculate from each $5 \mathrm{~s}$ mean PSD and flight-level reflectivity the variability of all possible solutions of $m(D)$ relationships fulfilling the condition that the simulated radar reflectivity factor ( $\mathbf{T}$-matrix method) matches the measured radar reflectivity factor. For the reflectivity simulations, ice crystals were approximated as oblate spheroids, without using a priori assumptions on the mass-size relationship of ice crystals. The CWC calculations demonstrate that individual CWC values are in the range $\pm 32 \%$ of the retrieved average $\overline{\mathrm{CWC}}$ value over all CWC solutions for the chosen $5 \mathrm{~s}$ time intervals. In addition, during the airborne field campaign performed out of Darwin in 2014, as part of the international High Altitude Ice Crystals/High Ice Water Content (HAIC/HIWC) projects, CWCs were measured independently with the new IKP-2 (isokinetic evaporator probe) instrument along with simultaneous particle imagery and radar reflectivity. Retrieved $\overline{\mathrm{CWC}}$ s from the $\mathbf{T}$-matrix radar reflectivity simulations are on average $16 \%$ higher than the direct $\mathrm{CWC}_{\mathrm{IKP}}$ measurements. The differ-
\end{abstract}

ences between the $\mathrm{CWC}_{\mathrm{IKP}}$ and averaged retrieved $\overline{\mathrm{CWC}} \mathrm{s}$ are found to be primarily a function of the total number concentration of ice crystals. Consequently, a correction term is applied (as a function of total number concentration) that significantly improves the retrieved CWC. After correction, the retrieved $\overline{\mathrm{CWC}}$ s have a median relative error with respect to measured values of only $-1 \%$. Uncertainties in the measurements of total concentration of hydrometeors are investigated in order to calculate their contribution to the relative error of calculated $\overline{\mathrm{CWC}}$ with respect to measured $\mathrm{CWC}_{\mathrm{IKP}}$. It is shown that an overestimation of the concentration by about $+50 \%$ increases the relative errors of retrieved $\overline{\mathrm{CWC}}$ by only $+29 \%$, while possible shattering, which impacts only the concentration of small hydrometeors, increases the relative error by about $+4 \%$. Moreover, all cloud events with encountered graupel particles were studied and compared to events without observed graupel particles. Overall, graupel particles seem to have the largest impact on high crystal number-concentration conditions and show relative errors in retrieved $\overline{\mathrm{CWC}}$ s that are higher than for events without graupel particles. 


\section{Introduction}

Clouds play an important role within the hydrological cycle, radiative transfer, and heat balance of the Earth. Thus, improving knowledge of ice hydrometeor properties and understanding of related processes is important for improving numerical weather forecast and global climate models, as such models use simple schemes to describe the ice hydrometeors' properties. As a consequence, significant differences in the representation of ice properties in clouds (Li et al., 2005, 2007) lead to large variations in the quantification of ice cloud effects on climate evolution (Intergovernmental Panel on Climate Change Fourth Assessment Report). Among different ice properties, the spatiotemporal distribution of cloud condensed water content (CWC) is a key parameter for evaluating and improving numerical weather prediction (Stephens et al., 2002). Increasingly, remote sensing tools are used to study cloud properties such as hydrometeor size distributions (ice or water), liquid and/or ice water content, ice particle shape (spherical, hexagonal, etc.), and precipitation rate. In particular, the radar (at different frequencies of 5.5, 9.4, 35, $94 \mathrm{GHz}$ ) is the most common measurement technique used to measure clouds properties. Radar reflectivity factors are an integral value of all backscattering cross sections from all hydrometeors within the radar sampling volume, which makes the radar a complex measurement device for estimating cloud properties.

The methodology applied in this study to simulate $94 \mathrm{GHz}$ radar reflectivity factors is based on assumptions about individual cloud particle properties. If hydrometeors are droplets, then Mie solutions can be applied to the Maxwell equations; however, this is not the case for non-spherical ice crystals. Discrete dipole approximations (DDA; Draine and Flatau, 1994; Liu, 2008) can be used to calculate backscatter cross sections for complex shapes and thus tackle this question for ice crystals. However, in order to apply DDA simulations to ice crystal radar reflectivity factors, a classification of ice hydrometeor habits is essential. Unfortunately, more than $50 \%$ of ice crystal images classified using automated or manual shape recognition techniques from ground-based and airborne measurements are typically identified as irregular (i.e. they are not identified as a specific habit). This statement still holds when using very-high-resolution imaging such as from the Cloud Particle Imager $(2.3 \mu \mathrm{m}$ resolution; e.g. Mioche, 2010).

Hogan et al. (2011) used the oblate spheroid approximation to simulate radar reflectivity factors at 3 and $94 \mathrm{GHz}$. For their calculation of the ice fraction in horizontally oriented oblate spheroids, these authors used a constant axis ratio of 0.6 and used the mass-size relationship from Brown and Francis (1995), originally from Locatelli and Hobbs (1974), to derive CWCs and radar reflectivity factors. Even though a mass-size relationship for ice crystals with constant coefficients has been utilized, the study of Hogan et al. (2011) claimed minimal errors between measured and simulated radar reflectivity factors, even smaller than the calibration uncertainty of the cloud radar.

Fontaine et al. (2014) also used the oblate spheroid approximation for ice crystals to calculate CWC in mesoscale convective systems (MCS), and Drigeard et al. (2015) used the Fontaine et al. (2014) results to simulate radar reflectivity factors at $5.5 \mathrm{GHz}$. Although simulations of radar reflectivity factors agreed with reflectivity observations at 94 and $5.5 \mathrm{GHz}$, no direct bulk measurements of CWC were available to evaluate the retrieved CWCs.

A simpler way to calculate CWC from radar reflectivity factors is based on empirical $Z-C W C$ or $Z-C W C-T$ relationships. Such relationships have been established in earlier studies, either with or without direct measurements of CWC (Protat et al., 2016, 2007; Hogan et al., 2006), for different types of clouds and at different geographical locations (tropics, continental, mid-latitude). When no direct simultaneous measurements of CWC are available, Z-CWC (and $Z-C W C-T$ ) relationships are established by using constant mass-size relationships (for CWC calculations from particle size distribution (PSD) measurements) and most of the time these studies use $m(D)$ coefficients suggested by Brown and Francis (1995). As a matter of fact this would mean that mass-size coefficients are constant and are linked neither to temperature nor to the variability of PSDs or the type of clouds. In Fontaine et al. (2014), these simplistic assumptions were not used. This more sophisticated method allows for a more dynamic solution with varying mass-size coefficients related to the variability of microphysics (PSD and aspect ratio of ice crystals). Fontaine et al. (2014) end up with the retrieval of an average CWC calculated as a function of time from multiple possible $m(D)$ solutions for the $\mathbf{T}$-matrix simulations of the radar reflectivity factor $(\mathrm{Ze})$ simulations compared to measured $Z$. The method has been established and published without validation from simultaneous direct measurements of CWC.

During the High Altitude Ice Crystals (HAIC; Dezitter et al., 2013)/High Ice Water Content (HIWC; Strapp et al., 2016) airborne field campaign performed out of Darwin, the Falcon-20 (F-20) from SAFIRE (Service des Avions Français Instrumentés pour la Recherche en Environnement) measured on the same aircraft $94 \mathrm{GHz} Z$, PSD, aspect ratios of hydrometeors, and independently CWC. The objective of our study is to use this comprehensive HAIC/HIWC dataset to evaluate the method presented by Fontaine et al. (2014).

The next section of this paper presents the dataset of the first HAIC/HIWC airborne campaign and associated data processing. The principle of the cloud radar reflectivity simulation method (Fontaine et al., 2014) is then briefly recalled. The third section is dedicated to the evaluation of the Fontaine et al. (2014) method by comparing averaged in retrieved $\overline{\mathrm{CWC}}$ s from the T-matrix simulations with direct measurements of $\mathrm{CWC}_{\mathrm{IKP}}$. Moreover, the study suggests correction functions for calculated $\overline{\mathrm{CWC}}$ (based on $\mathbf{T}$-matrix simulations of the reflectivity factors) as a function of tem- 
perature, largest size of hydrometeors in PSDs, and ice crystal concentrations. Then, two further sections are dedicated to the estimation of possible uncertainties in the measurements leading to the corrected $\overline{\mathrm{CWC}}$ retrievals and the impact of graupel particles on those retrievals. Finally, the study ends with a discussion and conclusion section.

\section{Data processing}

The HAIC/HIWC projects were designed to investigate the microphysical processes responsible for engine damage observed when commercial aircraft divert around convective cores. First HIWC studies (Mason et al., 2006) indicated that this new form of icing (now referred to as ice crystal icing) was due to the production of high concentrations of small ice crystals by deep convection. In this context 23 flights were performed over the Darwin area, mainly over the ocean north of Australia, during the monsoon season. Three of the 23 flights were dedicated to the calibration of the instruments and are not included in this study. The dataset includes more than 17000 data points where all parameters are synchronized and averaged over $5 \mathrm{~s}$. As one of the priority of the HAIC/HIWC projects was to measure high ice water content and the variability of CWC as a function of distance from the convective cores at typical altitudes flown by commercial aircraft, the flight strategy was to fly long legs at constant altitude at $-50,-40,-30$, and $-10^{\circ} \mathrm{C}$ and to get as close as possible to the most convective zone of the MCS (see Fig. 2 in Leroy et al., 2017), thereby avoiding red aircraft radar echoes at normal gain as commercial aircraft would also do. More details on HAIC/HIWC projects and implemented flight strategy can be found in Dezitter et al. (2013), Leroy et al. (2016, 2017), Protat et al. (2016), and Strapp et al. (2016).

In situ microphysical measurements and radar reflectivity data used in this study were provided by three types of instruments, which were mounted on board the F-20 for the HAIC/HIWC Darwin campaign.

(1) The $94 \mathrm{GHz}$ multi-beam Doppler cloud radar RASTA measured both cloud radar reflectivity factors and 3-D cloud dynamics below and above the flight level. The uncertainty on the measured reflectivity is about $\pm 1 \mathrm{dBZ}$ (e.g. Protat et al., 2009). We only use radar vertical antennas (zenith, nadir) producing vertical profiles of the radar reflectivity along the flight trajectory. Radar reflectivity factors are interpolated at the flight altitude using validated gates (typically $180 \mathrm{~m}$ above and below the aircraft) to retrieve the most likely radar reflectivity at flight altitude. RASTA has a vertical resolution of $60 \mathrm{~m}$ and $0.7^{\circ}$ beam width.

(2) Two optical array probes (OAPs), the 2-D-Stereo probe (2-D-S) from SPEC (Stratton Park Engineering Company, Inc.) and the Precipitation Imaging Probe (PIP) from Droplet Measurement Technologies (DMT) were used.
(3) An Isokinetic Evaporator Probe (IKP-2: Davison et al., 2016) that provides direct CWC measurements was also used. The IKP-2 is a second-generation version of the prototype IKP (Davison et al., 2008), which was downsized for the F-20. The IKP-2 was developed to provide reliable measurements of CWC in deep convective clouds at temperatures colder than $-10^{\circ} \mathrm{C}$, up to at least $10 \mathrm{~g} \mathrm{~m}^{-3}$ at aircraft speeds of $200 \mathrm{~ms}^{-1}$, and with a target accuracy of $20 \%$. The IKP-2 samples the cloud particles isokinetically, evaporates them, and measures the resulting humidity of the evaporated particles and background air. CWC (hereafter $\mathrm{CWC}_{\mathrm{IKP}}$ given in $\mathrm{g} \mathrm{m}^{-3}$ ) is then obtained by subtracting the water vapour background measurement from the IKP-2 total hygrometer signal. System accuracy estimates are better than $20 \%$ for CWC greater than $0.25 \mathrm{~g} \mathrm{~m}^{-3}$ for temperatures lower than $-10^{\circ} \mathrm{C}$ (Davison et al., 2016). Accuracy increases with decreasing temperature due to the exponential decrease in background humidity, which drives much of the IKP-2 error. For example, at $-56^{\circ} \mathrm{C}$, system accuracy was estimated at better than $4 \%$ for $\mathrm{CWC}$ greater than about $0.1 \mathrm{~g} \mathrm{~m}^{-3}$.

The 2-D-S and the PIP record monochromatic 2-D shadow images of cloud hydrometeors (ice and/or water) along the flight trajectories. The 2-D-S records images of hydrometeors in the size range $10-1280 \mu \mathrm{m}$ at a $10 \mu \mathrm{m}$ pixel resolution, whereas the PIP records images in the size range 100 $6400 \mu \mathrm{m}$ and beyond (perpendicular to photodiode array and reconstruction of truncated images parallel to the array) at a $100 \mu \mathrm{m}$ pixel resolution. For both probes, PSDs were produced by image analysis into number concentrations per unit volume of sampled air as a function of their size.

In this paper, the size of ice hydrometeors is given in terms of the maximum diameter $D_{\max }$ (e.g. see Leroy et al., 2016, for definition). The size of truncated images and sampling volume are corrected using the method presented in Korolev and Sussman (2000). This reconstruction method allows extrapolating hydrometeor sizes to a maximum size of $2.56 \mathrm{~mm}$ for 2-D-S and to $12.8 \mathrm{~mm}$ for PIP.

In addition, many artefacts can bias PSD estimates from 2D image analysis. Therefore, supplementary post-processing is needed to retain only the natural ice particles. One of the most important causes of artefacts is the shattering of hydrometeors on the tips of OAPs. During the first HAIC/HIWC field campaign in Darwin, the newest antishattering tips were used for 2-D-S and PIP to reduce the shattering from large ice crystals. In addition, analysis of the time-dependent (along the flight trajectory) interarrival time spectra was performed to determine the cut-off time, which separates natural hydrometeors images from artefact particles (Korolev and Isaac, 2005; Field et al., 2006; Korolev and Field, 2015). It has been shown that both mitigation techniques are needed to maximize the removal of shattering artefacts (Jackson et al., 2014). Furthermore, OAP images (for both 2-D-S and PIP) of splashed hydrometeors were removed using the ratio between their projected surface area and the surface defined by the box Lx $\times$ Ly (e.g. see Dx and 
Dy in Leroy et al., 2016), where Lx is the projection of the size of each hydrometeor along the flight trajectory, and Ly is the projection along the array of diodes. Images with an area ratio less than 0.25 were considered as splashed particles and removed. This threshold has been calculated statistically and allows the removal of larger splashed ice crystals as well.

Another important correction is related to the sizing of outof-focus hydrometeors. In our study, the size of out-of-focus particles was corrected using the method presented in Korolev (2007). In addition, noisy pixels (satellite pixels) which may affect hydrometeor images were eliminated thereby applying the method described in Lawson (2011). These singlepixel noisy pixels are not firmly attached to the hydrometeors' images and therefore must be removed to get the best estimation of the true diameter (e.g. $D_{\max }$ ).

Finally, high number concentrations of ice particles lead to gaps in the sampling times of OAPs due to insufficient time to record all hydrometeors images. This probe effect (also called OAP overload or dead time) was taken into account and would otherwise lead to an underestimation of the number concentration of hydrometeors. While the 2-D-S probe overload times are directly registered, the PIP overload is estimated by comparing the number of images in the PIP files to the separately registered total particle counts of particles that passed through the laser beam. The ratio of counted particles (1-D information) to recorded particle images (2-D information) is used to correct for the concentration. During an OAP overload, 1-D counted particles may reach 15000 while only about 10000 have a recorded image, which would result in an uncertainty of $50 \%$ on the concentration of hydrometeors, without overload correction (Fontaine, 2014). Further details on post-processing of 2-D-S and PIP data are given in Leroy et al. (2016). The individual 2-D-S and PIP PSDs were merged into a composite PSD using the algorithm described in Eq. (1). The resolution of the composite PSD is $10 \mu \mathrm{m}$ (by interpolating the PIP raw PSDs at the 2-D-S resolution), and PSDs are averaged over $5 \mathrm{~s}$ time intervals for improved large particle statistics. The transition zone for changing from 2-D$\mathrm{S}$ to PIP data in the composite spectrum (see equation below) is from a $D_{\max }$ of $805 \mu \mathrm{m}$ (median diameter for a size bin) to $1205 \mu \mathrm{m} . N\left(D_{\max }\right)$ is given per litre.

$$
\begin{aligned}
& \sum_{D_{\max }=15}^{D_{\max }=12845} N\left(D_{\max }\right) \cdot \Delta D_{\max } \\
&= \sum_{D_{\max }=15}^{D_{\max }<805} N_{2-\mathrm{D}-\mathrm{S}}\left(D_{\max }\right) \cdot \Delta D_{\max }+C_{1}\left(D_{\max }\right) \\
& \cdot \sum_{D_{\max }=805}^{D_{\max }<1205} N_{2-\mathrm{D}-\mathrm{S}}\left(D_{\max }\right) \cdot \Delta D_{\max } \\
&+C_{2}\left(D_{\max }\right) \sum_{D_{\max }=805}^{D_{\max }<1205} N_{\mathrm{PIP}}\left(D_{\max }\right) \cdot \Delta D_{\max }
\end{aligned}
$$

$$
+\sum_{D_{\max }=1205}^{D_{\max }=12845} N_{\mathrm{PIP}}\left(D_{\max }\right) \cdot \Delta D_{\max },
$$

where $C_{1}\left(D_{\max }\right)+C_{2}\left(D_{\max }\right)=1$, with $C_{2}\left(D_{\max }\right)=$ $\frac{D_{\max }-805}{1205-805}$.

\section{Retrievals of CWC from radar reflectivity simulations}

\subsection{Simulations of radar reflectivity factors: Ze}

This section reviews the method used in Fontaine et al. (2014). The principle of the technique is to retrieve CWC from simulations of radar reflectivity factors (Ze), calculated from OAP image information and compared to measured RASTA radar data. The data were collected in tropical MCSs that formed over the African continent and over the Indian Ocean during two aircraft campaigns dedicated to the Megha-Tropiques project (Roca et al., 2015). The main drawback of these experiments is that they do not include direct measurement of CWC. The Fontaine et al. (2014) method uses oblate spheroids (Hogan et al., 2011) to approximate the backscatter cross section ( $Q_{\text {back }}$ ) of natural hydrometeors. In Eq. (2) below, Ze is defined in $\mathrm{mm}^{6} \mathrm{~m}^{-3}$ :

$$
\begin{aligned}
& \operatorname{Ze}\left(\overline{\mathrm{As}}, f_{\text {ice }}\left(D_{\max }\right)\right)=1000 \cdot \frac{\lambda^{4}}{\pi^{5} \cdot\left|K_{\mathrm{w}-\mathrm{ref}}\right|} \\
& \sum_{D_{\max }=15}^{D_{\max }=12845} N\left(D_{\max }\right) \cdot Q_{\text {back }}\left(\overline{\mathrm{As}}, f_{\text {ice }}\left(D_{\max }\right)\right) \\
& \cdot \Delta D_{\max },
\end{aligned}
$$

with

$$
f_{\text {ice }}=\min \left(1, \frac{m\left(D_{\max }^{\beta}\right)}{\frac{\pi}{6} \cdot \rho_{\text {ice }} \cdot D_{\max }^{3}}\right),
$$

where

$m\left(D_{\max }\right)=\alpha \cdot D_{\max }^{\beta}$,

and

$\overline{\mathrm{As}}=\sum_{D_{\max }=15}^{D_{\max }=12845} \operatorname{As}\left(D_{\max }\right) \cdot P i\left(D_{\max }\right)$,

where

$$
P i\left(D_{\max }\right)=\frac{N\left(D_{\max }\right) \cdot D_{\max }^{3} \cdot \Delta D_{\max }}{\sum_{D_{\max }=15}^{D_{\max }=12845} N\left(D_{\max }\right) \cdot D_{\max }^{3} \cdot \Delta D_{\max }} .
$$

Note that in Eq. (2) $\lambda$ is the emitted wavelength of the radar and $K_{\mathrm{w}-\text { ref }}$ is the dielectric constant of liquid water at the same frequency. $Q_{\text {back }}$ is a function of the ice fraction $\left(f_{\text {ice }}\right.$; 
Eq. 3) in the spheroid and the axis ratio of the oblate spheroid (here denoted $\overline{\mathrm{As}}$, see Eq. 5). $f_{\text {ice }}$ is thereby a function of the mass-size relationship (see Eq. 3). Equation (3) also limits the mass of an ice hydrometeor to the mass of an ice sphere of diameter $D_{\max }$. $f_{\text {ice }}$ also allows the calculation of the dielectric properties of the ice spheroids (Maxwell Garnet, 1904; Drigeard et al., 2015).

As (Eq. 5) is the average aspect ratio of all hydrometeors and is calculated every $5 \mathrm{~s}$ according to $N\left(D_{\max }\right)$ and $Z$. Pi (Eq. 6) is a weighting function that has been defined to account for the volume occupied by the hydrometeors in the sampled volume. As $\left(D_{\max }\right)$ for a particle is defined as the ratio of the width (radius perpendicular to $D_{\max }$ ) divided by $D_{\max }$. In Fontaine et al. (2014) the calculation of $\overline{\mathrm{As}}$ only considers all hydrometeors with sizes $D_{\max } \leq 2005 \mu$ which contribute on average to $95 \%$ of $\mathrm{Ze}$ (Drigeard et al., 2015). Since the processing of 2-D-S and PIP has been further improved by Leroy et al. (2016), we decided to consider all hydrometeors from $15 \mu \mathrm{m}$ to $1.2845 \mathrm{~cm}$ for $\overline{\mathrm{As}}$ calculation. Note that a comparison of the $\overline{\mathrm{As}}$ calculation utilized in Fontaine et al. (2014) with the new $\overline{A s}$ calculation results in a decrease of $\overline{\mathrm{As}}$ of less than $3 \%$, which has a negligible impact on the retrieval results.

Note that the constant aspect ratio of 0.6 used in Hogan et al. (2011) is rather close to the peak of the $\overline{\text { As }}$ frequency distribution presented for African monsoon MCS and also oceanic MCS over the Indian Ocean (Fontaine et al., 2014). The average aspect ratio calculated for the HAIC/HIWC dataset is 0.55 , which is then very similar to respective average values for the various datasets sampled over the African continent, United Kingdom, Indian Ocean, and north of Australia.

In Fontaine et al. (2014) the exponent $\beta$ of the $m(D)$ power law relationship has been constrained as a function of time from the ice particle images. For this study, no a-priori assumptions on the mass-size relationship of hydrometeors have been chosen and therefore a variational approach has been applied to calculate CWC from Ze reflectivity factor simulations. For a given but variable exponent $\beta_{i}$ the corresponding pre-factor $\alpha_{i}$ is calculated to match the measured reflectivity $Z$ with the simulated $\mathrm{Ze}$. $\beta_{i}$ is varying stepwise between 1 to 3 by increments of 0.01 . Thereby, the range of potential solutions are explored using the oblate spheroids approximation with the T-matrix method (Mishchenko et al., 1996) calculating $Q_{\text {back }}$ of each spheroid. Hence, for a given $5 \mathrm{~s}$ data point, 201 calculations of $\alpha_{i}$ and 201 calculations of corresponding $\mathrm{CWC}\left(\beta_{i}\right)$ are performed (see Eq. 10):

$$
\begin{aligned}
\operatorname{CWC}\left(\beta_{i}\right) & =10^{3} \cdot \sum_{D_{\max }=15}^{D_{\max }=12845} N\left(D_{\max }\right) \cdot \alpha_{i} \cdot D_{\max }^{\beta_{i}} \\
\cdot \Delta D_{\max } . &
\end{aligned}
$$

For each $5 \mathrm{~s}$ data point, from the 201 possible $\operatorname{CWC}\left(\beta_{i}\right)$ values, an average value $\overline{\mathrm{CWC}}$ is deduced (Eq. 11):
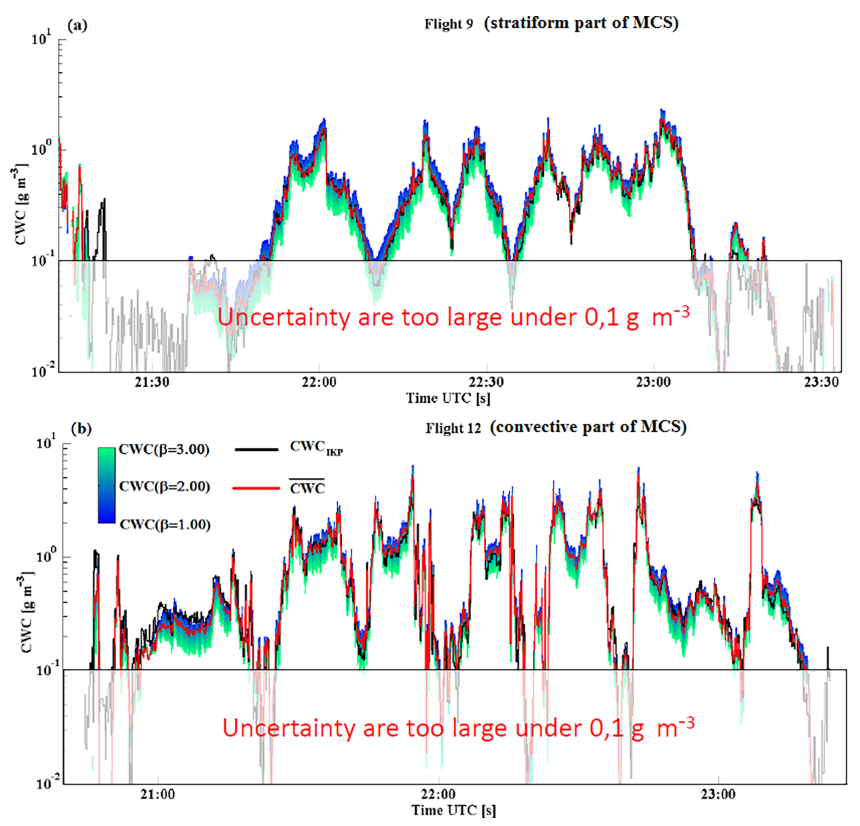

Figure 1. Condensed water content (CWC) as a function of time for two HAIC/HIWC flights during the Darwin 2014 flight campaign. In black is $\mathrm{CWC}_{\mathrm{IKP}}$; in red is the average $\overline{\mathrm{CWC}}$ deduced from all possible simulations (varying $\beta$ and constraining $\alpha$ ) of the measured $Z$. Blue-to-green colour band shows $\operatorname{CWC}\left(\beta_{i}\right)$ calculations when $\beta$ varies from 1 (blue) to 3 (green). (a) Results for flight 9; (b) results for flight 12 .

$\overline{\mathrm{CWC}}=\frac{1}{N_{\mathrm{tot}}} \cdot \sum_{\beta_{i}=1}^{\beta_{i}=3} \mathrm{CWC}\left(\beta_{i}\right)$,

where $N_{\text {tot }} \leq 201$, since the minimum value allowed for $\alpha_{i}$ is the mass of an empty sphere (air density).

Figure 1 shows two examples (flights 9 and 12) with all possible $\mathrm{CWC}\left(\beta_{i}\right)$ retrievals (colour band), average $\overline{\mathrm{CWC}}$ (red line), and $\mathrm{CWC}_{\mathrm{IKP}}$ measured by the IKP (overlaid black line). The example in Fig. 1a shows results from flight 9, in which the F-20 research aircraft flew in the more stratiform part of the cloud system $\left(w \sim 0 \mathrm{~m} \mathrm{~s}^{-1}\right)$, whereas results from flight 12 shown in Fig. 1b represent a case with more signatures of convective updrafts. Overall, Fig. 1 demonstrates that the variational retrieval method produces a large variability of possible $\operatorname{CWC}\left(\beta_{i}\right)$ for each $5 \mathrm{~s}$ data point. In general, the average $\overline{\mathrm{CWC}}$ (red line) is close to $\mathrm{CWC}_{\mathrm{IKP}}$. The bandwidth of all possible solutions $\mathrm{CWC}\left(\beta_{i}\right)$ as a function of time is calculated from the difference $\Delta \mathrm{CWC}=\max \left(\mathrm{CWC}\left(\beta_{i}\right)\right)-\min \left(\operatorname{CWC}\left(\beta_{i}\right)\right)$ between the maximum and the minimum values of $\mathrm{CWC}\left(\beta_{i}\right)$. On average, it is found that $\triangle \mathrm{CWC}$ accounts for $61 \%$ of $\overline{\mathrm{CWC}}$ (with $64 \%$ for the median relative error) for the entire dataset (20 flights performed over Darwin area). Finally, the calculations reveal that $80 \%$ of the HAIC dataset satisfy the condition 

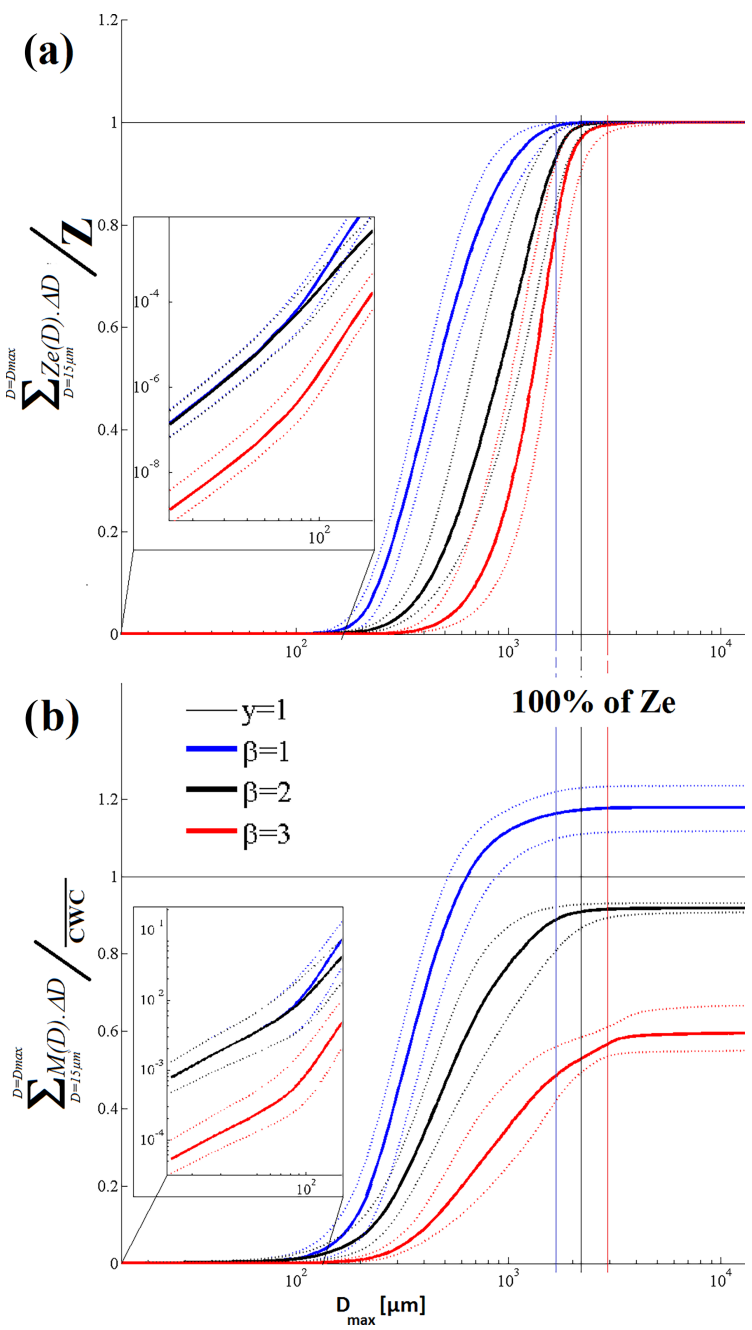

Figure 2. (a) Ratio of cumulative sum of simulated Ze over measured total $Z$ as a function of $D_{\max }$ for three chosen $\left(\alpha_{i}, \beta_{i}\right)$ solutions $(\beta=1,2$, and 3). (b) Ratio of the cumulative sum of ice crystal mass over the $\overline{\mathrm{CWC}}$ for constant $\beta(\beta=1,2$, and 3$)$, represented as a function of $D_{\max }$. Full lines represent median and dashed lines 25th and 75th percentiles for entire dataset with blue lines for $\beta=1$, black lines for $\beta=2$, and red lines for $\beta=3$.

$\mathrm{CWC}_{\mathrm{IKP}}=\overline{\mathrm{CWC}} \pm 32 \%$, where no a priori assumptions on mass-size relationships were applied and $\beta_{i}$ linearly varies between 1 and 3 , thereby producing equally eligible solutions $\operatorname{CWC}\left(\beta_{i}\right)$ that are finally averaged to produce a $5 \mathrm{~s}$ data point for $\overline{\mathrm{CWC}}$.

In general, and for each given $5 \mathrm{~s}$ data point, maximum CWC is obtained for $\beta=1$ and minimum CWC for $\beta=3$. For $\beta=1$, ice hydrometeors below $D_{\max }=200 \mu \mathrm{m}$ (sometimes even below $300 \mu \mathrm{m}$ ) may reach the maximum density of $0.917 \mathrm{~g} \mathrm{~cm}^{-3}$, while for $\beta=3$ the density of oblate spheroids is constant as a function of $D_{\max }$ (see Eqs. 3-4), where the density of icy spheroids is equal to $\left.0.917 \times f_{\text {ice }}\right)$.

The impact of $\beta$ on Ze and on the retrieved CWCs is illustrated in Fig. 2. One can notice that for different values

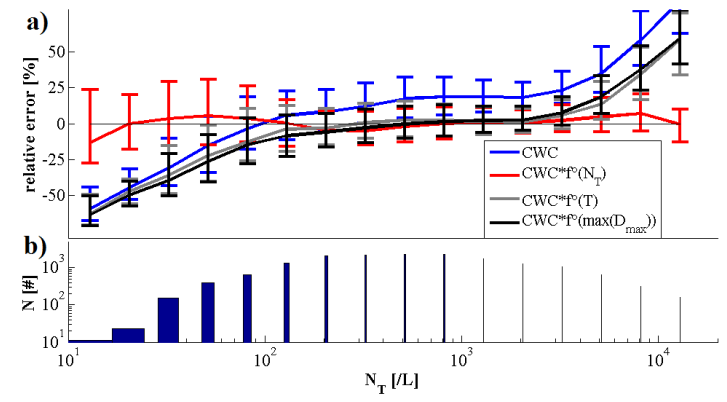

Figure 3. (a) Relative errors of $\overline{\mathrm{CWC}}$ with respect to $\mathrm{CWC}_{\mathrm{IKP}}$ (as defined in Table 1) as a function of total PSD number concentration $N_{\mathrm{T}}$. The errors are presented with and without the three suggested correction functions for $\overline{\mathrm{CWC}}$. (b) Number of $5 \mathrm{~s}$ data points used for the statistics on the $y$ axis as a function of $N_{\mathrm{T}}$ intervals.

of $\beta(\beta=1,2,3)$ the corresponding value of $\alpha$ can be found such that the cumulative sum of $\mathrm{Ze}$ as a function of $D_{\max }$ normalized by the measured radar reflectivity factor $Z$ (in $\mathrm{mm}^{6} \mathrm{~m}^{-3}$; Fig. 2a.) is equal to 1 . The respective cumulative mass of ice crystals (as a function of $D_{\max }$ ) then is normalized by $\overline{C W C}$ (Fig. 2b). This CWC ratio may deviate from 1 , whereas the normalized cumulative sum of $\mathrm{Ze}$ has been equal to 1 , independently of chosen $\beta$. For $\beta=1, \mathrm{Ze}$ is reached sooner $\left(D_{\max } \approx 1700 \mu \mathrm{m}\right)$ than for $\beta=3\left(D_{\max } \approx 3000 \mu \mathrm{m}\right)$. The likely explanation is that with increasing $\beta$, the backscattered energy is increased for large hydrometeors and the mass contribution of smaller hydrometeors is considerably reduced since the contribution of numerous smaller hydrometeors (compared to larger hydrometeors) on retrieved CWC is decreasing with increasing $\beta$.

\subsection{CWC deviations from T-matrix simulations of reflectivity with respect to IKP direct measurements}

This section focuses on the potential error in CWC retrievals from $\mathbf{T}$-matrix simulations of radar reflectivity factors (at frequency of $94 \mathrm{GHz}$ ) for populations of ice hydrometeors approximated with oblate spheroids. Therefore, the relative errors of retrieved $\overline{\mathrm{CWC}}$ with respect to reference $\mathrm{CWC}_{\mathrm{IKP}}$ (measured by the IKP-2 probe) are calculated and then analysed as a function of microphysical properties of ice hydrometeors such as total concentration ( $N_{\mathrm{T}}$; Fig. 3), temperature $T$ (Fig. 4), maximum size of hydrometeors in PSDs $\left(\max \left(D_{\max }\right)\right.$; Fig. 5), total cloud water content $\mathrm{CWC}_{\mathrm{IKP}}$ (Fig. 6), and radar reflectivity factors $Z$ (Fig. 7). Blue lines in Figs. 3-7 (upper charts) display median trends obtained when the relative errors of $\overline{\mathrm{CWC}}$ are plotted as a function of the crystal number concentration $N_{\mathrm{T}}$, the temperature $T$, the maximum encountered crystal size $\max \left(D_{\max }\right)$, the $C W C_{\mathrm{IKP}}$, and the radar reflectivity $Z$. Bottom and top whiskers of the error bars represent the 25th and 


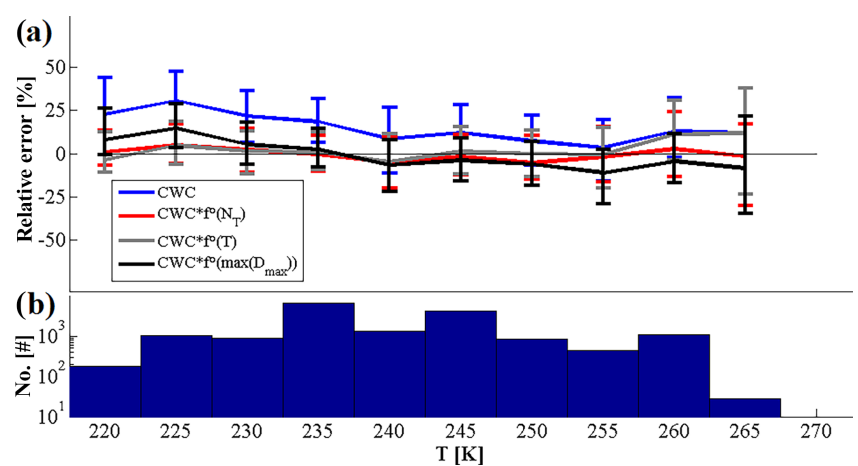

Figure 4. Same as Fig. 3, but represented as a function of temperature $T$ on the $x$ axis.

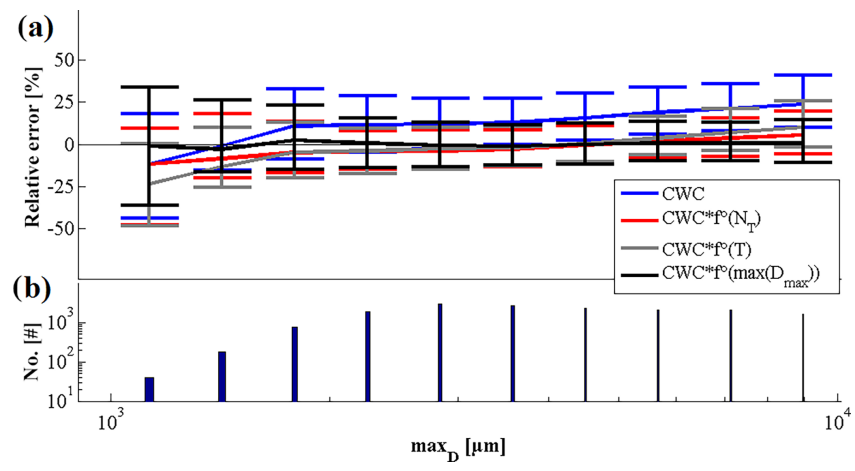

Figure 5. Same as Fig. 3 but represented as a function of the maximum size of hydrometeors $\max \left(D_{\max }\right)$ on the $x$ axis.

75th percentiles of the relative error of $\overline{\mathrm{CWC}}$ (with respect to

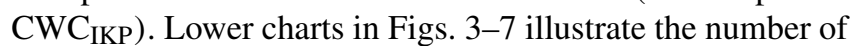
samples used for the calculation of the respective data points in discrete intervals of $N_{\mathrm{T}}, T, \max \left(D_{\max }\right), \mathrm{CWC}_{\mathrm{IKP}}$, and $Z$. The other curves in Figs. 3-7 represent the retrieved CWCs with applied corrections as a function of $N_{\mathrm{T}}$ (red curves), $T$ (grey curves), and $\max \left(D_{\max }\right)$ (black curves) and are discussed in Sect. 3.3 with the correction functions.

From Fig. 3 (blue line) it appears that $\overline{\mathrm{CWC}}$ resulting from $\mathbf{T}$-matrix simulations approximating ice hydrometeors with oblate spheroids is poorer at the lower $\left(N_{\mathrm{T}}<100 \mathrm{~L}^{-1}\right)$ and higher $\left(N_{\mathrm{T}}>5000 \mathrm{~L}^{-1}\right)$ ranges of number concentrations. In particular, the reference $\mathrm{CWC}_{\mathrm{IKP}}$ is underestimated for small $N_{\mathrm{T}}$ and overestimated for larger $N_{\mathrm{T}}$. Furthermore, Fig. 4 (blue line) seems to illustrate that this method increasingly overestimates with decreasing temperature (blue line in Fig. 4). For example, $\overline{\mathrm{CWC}}$ exceeds $\mathrm{CWC}_{\mathrm{IKP}}$ at $220 \mathrm{~K}$ $( \pm 5 \mathrm{~K})$ by about $25 \%$. Finally, the relative errors of $\overline{\mathrm{CWC}}$ with respect to $\mathrm{CWC}_{\mathrm{IKP}}$ slightly but continuously increase with the maximum size of hydrometeors within the respective data point (blue line in Fig. 5), where the relative error of $\overline{\mathrm{CWC}}$ reaches $+25 \%$ when $\max \left(D_{\max }\right)=1 \mathrm{~cm}$ versus $\sim 0 \%$ for $\max \left(D_{\max }\right)=800 \mu \mathrm{m}$.

\subsection{Correction functions for CWC retrievals from T-matrix simulations of reflectivity}

Because of the above findings, three different types of corrections are studied in order to (i) quantify the limitations of the oblate spheroid approximation and (ii) suggest suitable correction functions that use in situ measured quantities over the entire dataset with $\mathrm{CWC}_{\mathrm{IKP}}$ larger than $0.1 \mathrm{~g} \mathrm{~m}^{-3}$. These corrections are performed using the inverse of the original relative errors (blue lines) in Figs. 3-5 and aims at reducing the median relative errors to $0 \%$. The impact of these corrections on relative errors as a function of $N_{\mathrm{T}}, T$, and $\max \left(D_{\max }\right)$ is added to Figs. 3-7.

Red lines in Figs. 3-7 represent the relative error of $\overline{\mathrm{CWC}} \times f\left(N_{\mathrm{T}}\right)$ after applying a correction function $f\left(N_{\mathrm{T}}\right)$ as a function of $N_{\mathrm{T}}$ with

$$
\begin{aligned}
f\left(N_{\mathrm{T}}\right) & =0.84 \cdot\left(-0.3012 \cdot \log _{10}\left(N_{\mathrm{T}}\right)^{3}+2.658 \cdot \log _{10}\left(N_{\mathrm{T}}\right)^{2}\right. \\
& \left.-7.758 \cdot \log _{10}\left(N_{\mathrm{T}}\right)+8.493\right) .
\end{aligned}
$$

Grey lines in Figs. 3-7 represent the relative error of $\overline{\mathrm{CWC}} \times$ $f(T)$ after applying a correction function $f(T)$ as a function of $T$ with

$f(T)=0.84 \cdot(0.006528 \cdot T-0.517)$.

Black lines in Figs. 3-7 represent the relative error of $\overline{\mathrm{CWC}} \times f\left(\max \left(D_{\max }\right)\right)$ after applying a correction function $f\left(\max \left(D_{\max }\right)\right)$ as a function of $\max \left(D_{\max }\right)$ with

$$
\begin{aligned}
f\left(\max \left(D_{\max }\right)\right) & =0.84 \cdot\left(2.092 .10^{-9} \cdot \max \left(D_{\max }\right)^{2}\right. \\
& \left.-3.869 .10^{-5} \max \left(D_{\max }\right)+1.15\right) .
\end{aligned}
$$

Without the above correction functions, retrieved initial $\overline{\mathrm{CWC}}$ are larger than $\mathrm{CWC}_{\mathrm{IKP}}$ by about $19 \%$ on average (with a median value of $+16 \%$; Table 1 , first row). Therefore, all three correction functions (Eqs. 9-11) have a median factor of 0.84 in common that reduces the initial $\overline{\mathrm{CWC}}$ such that $\overline{\mathrm{CWC}} \times f\left(X ; X=N_{\mathrm{T}}, T, \max \left(D_{\max }\right)\right)$ better matches $\mathrm{CWC}_{\mathrm{IKP}}$. The expressions in parentheses of Eqs. (9)-(11) try to redistribute the relative error in $\overline{\mathrm{CWC}}$ from $\mathbf{T}$-matrix simulations over the entire range of observed $N_{\mathrm{T}}, T$, and $\max \left(D_{\max }\right)$ values, but they have negligible impact on the median relative error itself. Even though no correction functions for $\overline{\mathrm{CWC}}$ have been proposed as a function of $\mathrm{CWC}_{\mathrm{IKP}}$ and $Z$, Figs. 6 and 7 illustrate the impact of $N_{\mathrm{T}}, T$, and $\max \left(D_{\max }\right)$ correction functions (Eqs. 9-11) on the redistribution of the relative error also as a function of $\mathrm{CWC}_{\mathrm{IKP}}$ and $Z$.

Figure 3 reveals that $f\left(N_{\mathrm{T}}\right)$ (Eq. 9) decreases biases of retrieved $\overline{\mathrm{CWC}} \times f\left(N_{\mathrm{T}}\right)$ over the entire $N_{\mathrm{T}}$ bandwidth, while $f(T)$ (Eq. 10) and $f\left(\max \left(D_{\max }\right)\right)$ (Eq. 11) do not change the shapes of the relative error lines as compared to uncorrected $\overline{\mathrm{CWC}}$ relative errors (Fig. 3). Also, the function 
Table 1. Mean relative errors, 10th, 25th, 50th, 75th, and 90th percentiles (in \%) of retrieved $\overline{\mathrm{CWC}}$ with respect to CWC $\mathrm{IKP}_{\text {. Black numbers }}$ are for the entire dataset and bold numbers are respective relative errors for graupel events only.

\begin{tabular}{|c|c|c|c|c|c|c|}
\hline Relative error & Mean & 10th & 25 th & 50 th & 75th & 90th \\
\hline$\frac{\overline{\mathrm{CWC}}-\mathrm{CWC} \mathrm{CWP}_{\mathrm{IKP}}}{\mathrm{CWC} \mathrm{C}_{\mathrm{IKP}}} \cdot 100 \%$ & $\begin{array}{r}19 \\
(\mathbf{8 3})\end{array}$ & $\begin{array}{r}-14 \\
(6)\end{array}$ & $\begin{array}{r}2 \\
(32)\end{array}$ & $\begin{array}{r}16 \\
(75)\end{array}$ & $\begin{array}{r}32 \\
(\mathbf{1 0 1})\end{array}$ & $\begin{array}{r}54 \\
(\mathbf{1 3 3})\end{array}$ \\
\hline$\frac{\overline{\mathrm{CWC}} \cdot f\left(N_{\mathrm{T}}\right)-\mathrm{CWC} \mathrm{C}_{\mathrm{IKP}}}{\mathrm{CWC}_{\mathrm{IKP}}} \cdot 100 \%$ & $\begin{array}{r}2 \\
(\mathbf{1 6})\end{array}$ & $\begin{array}{r}-24 \\
(-25)\end{array}$ & $\begin{array}{l}-12 \\
(-7)\end{array}$ & $\begin{array}{l}-1 \\
(7)\end{array}$ & $\begin{array}{r}12 \\
(32)\end{array}$ & $\begin{array}{r}28 \\
(\mathbf{5 4})\end{array}$ \\
\hline$\frac{\overline{\mathrm{CWC}} \cdot f(T)-\mathrm{CWC}_{\mathrm{IKP}}}{\mathrm{CWC} \mathrm{C}_{\mathrm{IKP}}} \cdot 100 \%$ & $\begin{array}{r}4 \\
(\mathbf{5 9})\end{array}$ & $\begin{array}{l}-24 \\
(-5)\end{array}$ & $\begin{array}{l}-11 \\
(\mathbf{1 6})\end{array}$ & $\begin{array}{r}1 \\
(\mathbf{5 1})\end{array}$ & $\begin{array}{r}15 \\
(77)\end{array}$ & $\begin{array}{r}34 \\
(\mathbf{1 0 0})\end{array}$ \\
\hline$\frac{\overline{\mathrm{CWC}} \cdot f\left(\max \left(D_{\max }\right)\right)-\mathrm{CWC}_{\mathrm{IKP}}}{\mathrm{CWC}} \cdot 100 \%$ & $\begin{array}{r}3 \\
(\mathbf{5 3})\end{array}$ & $\begin{array}{r}-26 \\
(-11)\end{array}$ & $\begin{array}{l}-12 \\
(\mathbf{1 4})\end{array}$ & $\begin{array}{r}0 \\
(44)\end{array}$ & $\begin{array}{r}14 \\
(68)\end{array}$ & $\begin{array}{r}33 \\
(\mathbf{9 6})\end{array}$ \\
\hline
\end{tabular}

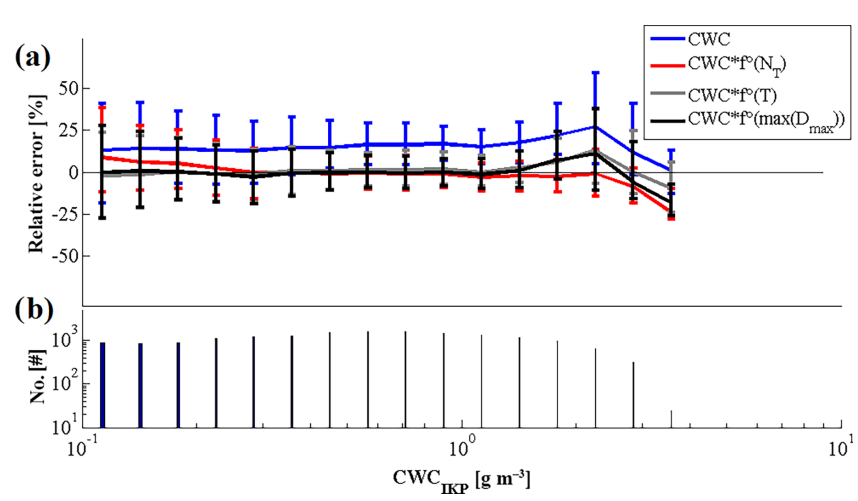

Figure 6. Same as Fig. 3 but represented as a function of $\mathrm{CWC}_{\mathrm{IKP}}$ on the $x$ axis.

$f\left(N_{\mathrm{T}}\right)$ (Eq. 9) also generally decreases relative errors of the $\overline{\mathrm{CWC}} \times f\left(N_{\mathrm{T}}\right)$ retrievals when plotted as a function of $T$ (Fig. 4) and as a function of $\max \left(D_{\max }\right)$ (Fig. 6). Furthermore, the $f(T)$ correction function (Eq. 10) reduces the differences between $\overline{\mathrm{CWC}} \times f(T)$ and $\mathrm{CWC}_{\mathrm{IKP}}$ as a function of $T$ (Fig. 4). However, $\overline{\mathrm{CWC}}$ s corrected as a function of $\mathrm{T}$ still show bias when presented as a function of $N_{\mathrm{T}}$ (Fig. 3, grey line) or as a function of $Z$ (Fig. 7, grey line). Finally, the $f\left(\max \left(D_{\max }\right)\right)$ correction function (Eq. 11) reduces the relative error of retrieved $\overline{\mathrm{CWC}} \times f\left(\max \left(D_{\max }\right)\right)$ as a function of $\max \left(D_{\max }\right)$ in Fig. 5 but does not have much impact on the shape of the relative error distributions as a function of $N_{\mathrm{T}}$, $T, \mathrm{CWC}_{\mathrm{IKP}}$, and $Z$ (Figs. 3, 4, 5, 7) relative to uncorrected $\overline{\mathrm{CWC}}$ relative errors.

In addition, rows $2-4$ of Table 1 present mean (average), median, 10th, 25th, 75th, and 90th percentiles of the relative error after applying the correction functions, with an obvious decrease of mean and median values and corresponding shift of relative error distribution percentiles.

Overall, the $f\left(N_{\mathrm{T}}\right)$ correction seems most efficient to remove the CWC bias. Heymsfield et al. (2013) showed that to-

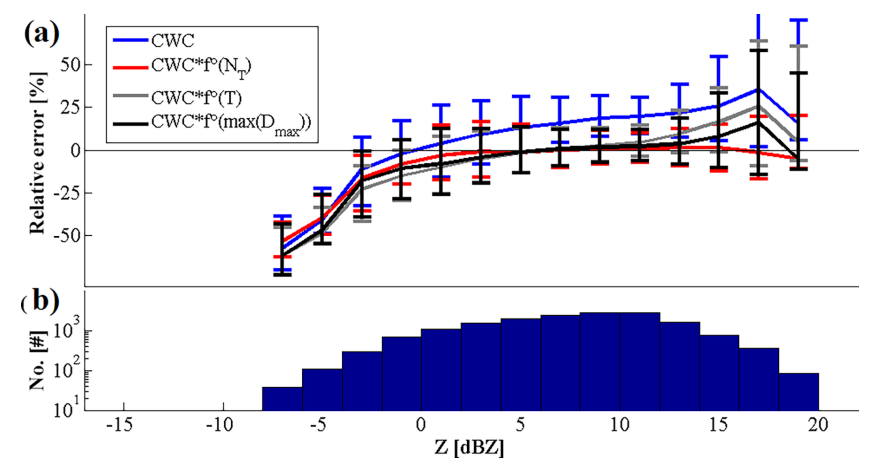

Figure 7. Same as Fig. 3 but represented as a function of radar reflectivity factors $Z$ on the $x$ axis.

tal concentrations of ice hydrometeors tend to increase with decreasing temperature in tropical MCS for temperatures $-60^{\circ} \mathrm{C}<T<0^{\circ} \mathrm{C}$. This evolution of the increasing total concentration of hydrometeors related to decreasing temperatures is therefore suggested as the key to explaining trends in relative CWC errors as a function of $N_{\mathrm{T}}$ and $T$.

Figure 8 summarizes the above results by showing probability distribution functions of $\overline{\mathrm{CWC}} \times f\left(X ; X=N_{\mathrm{T}}, T\right.$, $\left.\max \left(D_{\max }\right)\right)$ versus $C W C_{\text {IKP. Imperfections of the correc- }}$ tions described by Eqs. (10) and (11) are clearly visible in Fig. $8 \mathrm{c}$ and $\mathrm{d}$, where high $\mathrm{CWC}_{\mathrm{IKP}}$ values are still overestimated (as in Fig. 8a) by $\overline{\mathrm{CWC}} \times f(T)$ and $\overline{\mathrm{CWC}} \times$ $f\left(\max \left(D_{\max }\right)\right)$, respectively. The correction function $f\left(N_{\mathrm{T}}\right)$ (Eq. 9) produces the best results (Fig. 8b), where the maximum of the probability distribution function in $\overline{\mathrm{CWC}} \times$ $f\left(N_{\mathrm{T}}\right)$ versus $\mathrm{CWC}_{\mathrm{IKP}}$ representation follows the line $y=x$. 
(a)
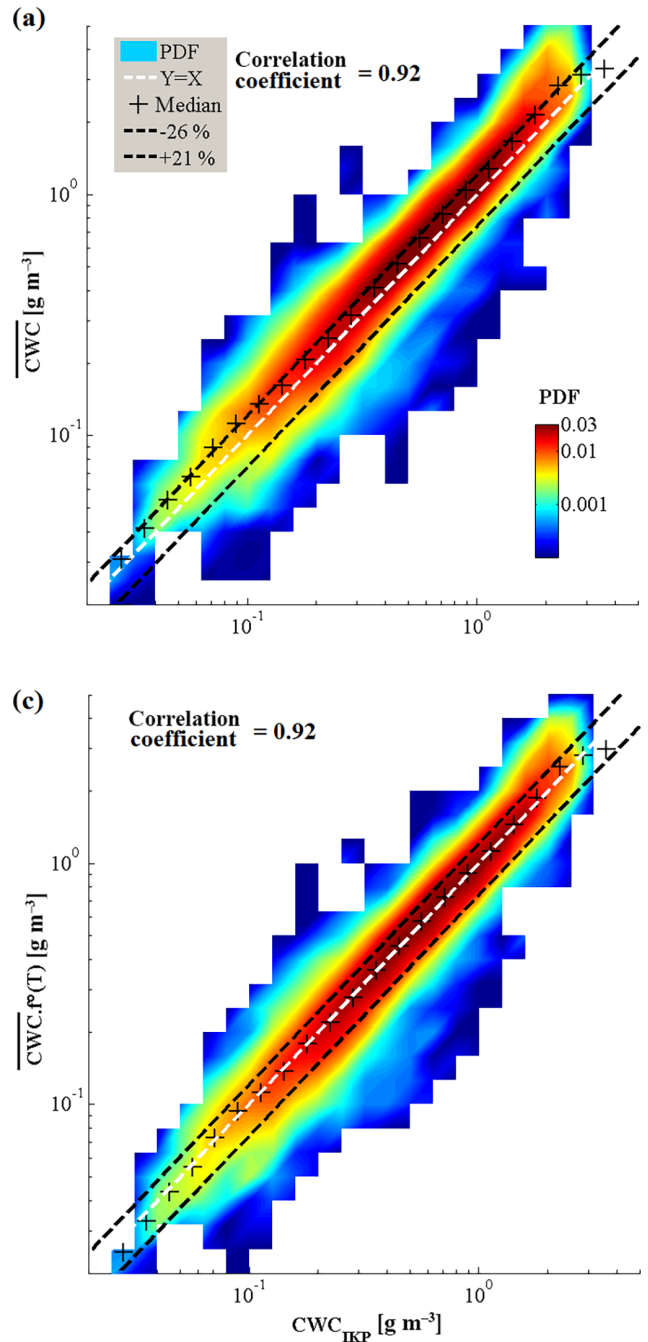
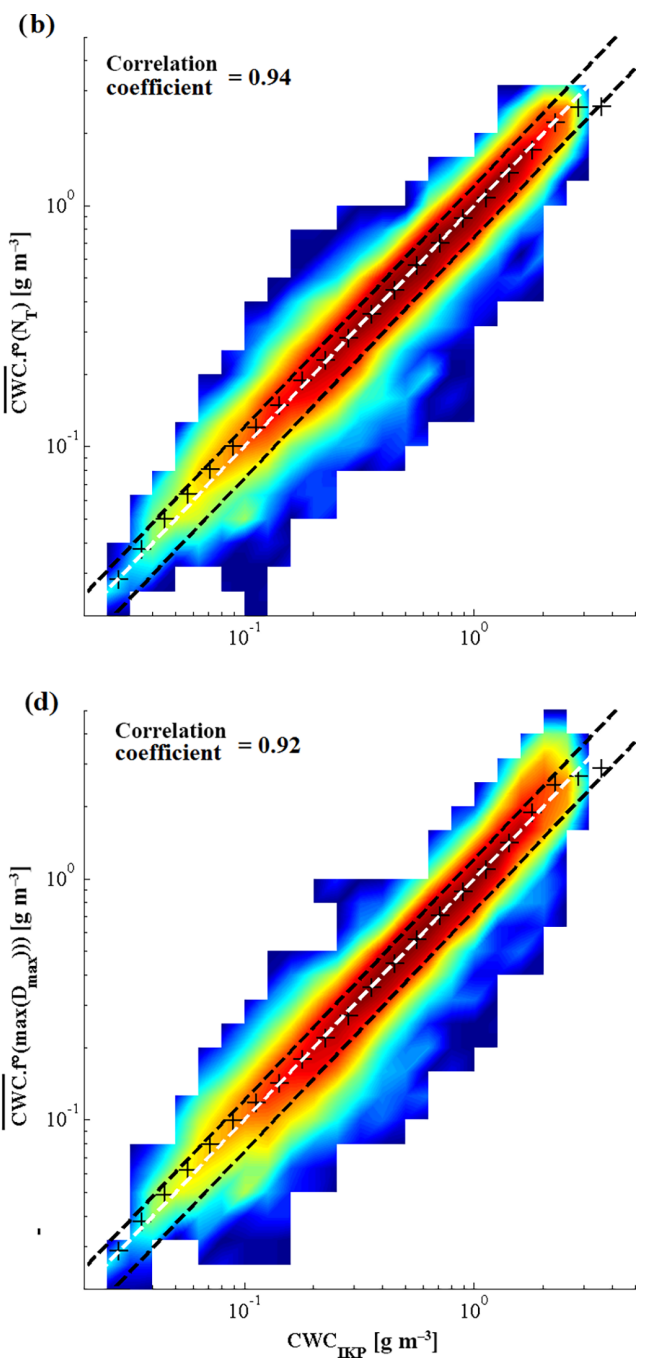

Figure 8. Probability distribution functions of $\overline{\mathrm{CWC}}$ on the $y$ axis calculated as a function of $\mathrm{CWC}_{\mathrm{IKP}}$ on the $x$ axis. Probabilities are represented by the colour scale and were normalized by the number of data points. (a) No correction is applied to average $\overline{\mathrm{CWC}}$. (b) Correction $f\left(N_{\mathrm{T}}\right)$ described by Eq. (9) is applied to $\overline{\mathrm{CWC}}$. (c) Correction $f(T)$ described by Eq. (10) is applied to $\overline{\mathrm{CWC}}$. (d) Correction $f\left(\max \left(D_{\max }\right)\right)$ described by Eq. (11) is applied to $\overline{\mathrm{CWC}}$. Dashed black lines represent the shift of retrieved CWSs when $Z$ is shifted by more or less $1 \mathrm{dBZ}$ (RASTA uncertainty; Fontaine et al. 2014).

Table 2. Relative errors of retrieved prefactor $\alpha_{i, \text { fshatt }}$ and $\alpha_{i, 50 \%}$ with respect to $\alpha_{i}$ in $\%$ for $\beta=[1,2,3]$.

\begin{tabular}{rrrr|rrr}
\hline & \multicolumn{2}{c|}{$100\left(\alpha_{i, \text { fshatt }}-\alpha_{i}\right) / \alpha_{i}$} & \multicolumn{3}{c}{$100\left(\alpha_{\left.i, 50 \%-\alpha_{i}\right) / \alpha_{i}}\right.$} \\
\cline { 2 - 7 } & 1st & Median & 99th & 1 st & Median & 99th \\
\hline$\beta=1$ & $-3 \%$ & $-3 \%$ & $1 \%$ & $-21 \%$ & $-18 \%$ & $-18 \%$ \\
$\beta=2$ & $-3 \%$ & $0 \%$ & $0 \%$ & $-20 \%$ & $-20 \%$ & $-18 \%$ \\
$\beta=3$ & $-3 \%$ & $0 \%$ & $0 \%$ & $-24 \%$ & $-20 \%$ & $-18 \%$ \\
\hline
\end{tabular}

\section{Uncertainties in ice particle concentrations and impact on results}

This section investigates the impact of uncertainties in crystal concentrations on the CWC retrieval, with a particular focus on shattering of ice crystals. As discussed in Sect. 3.2 the relative errors increase with total number concentration, with overestimations by about $50 \%$ of CWCs for very large concentrations of hydrometeors, which can reach $10^{4}$ hydrometeors per litre in most convective parts of sampled MCS (Fig. 3a). In order to investigate the impact of uncertainties of number concentrations on the retrieved CWC we apply two different types of functions on the measured PSDs, in which both functions increase the number concentrations of measured PSDs. 
Table 3. Relative errors of retrieved $\mathrm{CWC}_{i}$, fshatt and $\mathrm{CWC}_{i, 50 \%}$ with respect to $\mathrm{CWC}_{i}$ in $\%$ for $\beta=[1,2,3]$.

\begin{tabular}{rrrr|rrr}
\hline & \multicolumn{2}{c}{$100\left(\mathrm{CWC}_{i, \text { fshatt }}-\mathrm{CWC}_{i}\right) / \mathrm{CWC}_{i}$} & \multicolumn{2}{|c}{$100\left(\mathrm{CWC}_{i, 50 \%}-\mathrm{CWC}_{i}\right) / \mathrm{CWC}_{i}$} \\
\cline { 2 - 6 } & 1 st & Median & 99 th & $1 \mathrm{st}$ & Median & 99 th \\
\hline$\beta=1$ & $-1 \%$ & $+4 \%$ & $+9 \%$ & $+23 \%$ & $+29 \%$ & $+32 \%$ \\
$\beta=2$ & $-1 \%$ & $+3 \%$ & $+9 \%$ & $+24 \%$ & $+27 \%$ & $+30 \%$ \\
$\beta=3$ & $+1 \%$ & $+1 \%$ & $+5 \%$ & $+22 \%$ & $+27 \%$ & $+30 \%$ \\
\hline
\end{tabular}

First, a function $f_{\text {shatt }}$ is applied to the PSD in order to increase concentrations of hydrometeors in the first PSD size bin $(5-15 \mu \mathrm{m})$ by about $50 \%$, while concentrations of hydrometeors larger than $500 \mu$ remain unchanged. The function $f_{\text {shatt }}$ decreases in a logarithmic way with $D_{\max }$ from first bin to $500 \mu \mathrm{m}$. $f_{\text {shatt }}$ is applied to PSD such that $N^{\prime}\left(D_{\max }\right)=f_{\text {shatt }}\left(D_{\max }\right) \times N\left(D_{\max }\right)$ and aims to produce new PSDs where the optimized probe tips still would have produced shattered crystal fragments and/or removal processing would have failed to remove numerous shattered ice particles. Then, the retrieval method (see Sect. 3.1) is applied to these new PSDs in order to calculate new values for $\alpha_{i}$ and subsequently $\mathrm{CWC}_{i}$ (hereafter $\alpha_{i}$, fshatt and $\mathrm{CWC}_{i \text {,fshatt }}$ ). For the purpose of this Sect. 4 , the method was only applied for $\beta=[1,2,3]$ in order to get a good idea of the maximum impact of possible shattering artefacts. Results are presented in terms of relative errors in Table 2 for $\alpha_{i \text {,fshatt }}$ and Table 3 for $\mathrm{CWC}_{i, \text { fshatt }}$, respectively. Relative errors in (\%) are calculated with respect to coefficients $\alpha_{i}$ and $\mathrm{CWC}_{i}$ (for $\beta=[1,2$, $3])$ calculated in Sect. 3 for non-modified original $N\left(D_{\max }\right)$ size distributions and without correction functions discussed in Sect. 3.3. (Eqs. 9 to 11). The relative errors illustrate that the chosen concentration increase of solely small hydrometeor sizes has very limited impact on retrieved $\alpha_{i}$ and $\mathrm{CWC}_{i}$. Indeed, we observe that the median relative error of the prefactor $\alpha_{i, \text { fshatt }}$ with respect to $\alpha_{i}$ is roughly $-3 \%$ for $\beta=1$ and $0 \%$ for $\beta=2$ and $\beta=3$. The 1 st and 99th percentiles are shown in order to demonstrate that the relative errors in $\alpha_{i, \text { fshatt }}$ are small over the entire dataset. Consecutively, median relative errors of $\mathrm{CWC}_{i}$, fshatt with respect to $\mathrm{CWC}_{i}$ are of the order of 4,3 , and $1 \%$ for $\beta=1,2$, and 3 , respectively. The 99th percentile of the relative error does not exceed $10 \%$ in retrieved CWC.

Second, a simple concentration uncertainty factor of 1.5 is applied over the entire measured size range, which increases the number concentration by $50 \%$ such that $N^{\prime}\left(D_{\max }\right)=$ $\left(1.5 \times N\left(D_{\max }\right)\right)$. Note that $50 \%$ is approximatively the missed number of ice crystal images by the PIP due to the probe overload in high concentrations of ice crystals, though data have been corrected for overload times (see Sect. 2 and Fontaine, 2014). Simulations of the reflectivity factor with modified $N^{\prime}\left(D_{\max }\right)$ were performed with resulting prefactor $\alpha_{i, 50 \%}$ and derived $\mathrm{CWC}_{i, 50 \%}$. Results of the comparison of $\alpha_{i, 50 \%}$ and $\mathrm{CWC}_{i, 50 \%}$ with $\alpha_{i}$ and $\mathrm{CWC}_{i}$, respectively, are also presented in Table 2 and Table 3. Globally, this second scenario of concentration enhancement of original PSD has a larger impact on retrieved prefactor $\left(\alpha_{i}\right)$ and calculated $\mathrm{CWC}_{i}$ than was the case for the first scenario. Indeed, adding $50 \%$ to the concentrations of hydrometeors results in a median decrease of prefactor $\alpha_{i, 50 \%}$ with respect to $\alpha_{i}$ of $-18 \%$ for $\beta=1$ and $-20 \%$ for both $\beta=2$ and 3 . The forced decrease in $\alpha$ (from $\alpha_{i, 50 \%}$ to $\alpha_{i}$, goes along with an increase of $\mathrm{CWC}_{i, 50 \%}$ with respect to $\mathrm{CWC}_{i}$ by about $+29 \%$ (for $\beta=1$ ) and $+27 \%$ for $\beta=2$ and 3. Indeed, for a given radar reflectivity factor we simulate (and measure) the same Ze (and $Z$ ) for $N^{\prime}\left(D_{\max }\right)$ (and $N\left(D_{\max }\right)$ ) with decreasing $\alpha$ ( $\alpha_{i, 50 \%}$ compared to $\alpha_{i}$,), while the $\mathrm{CWC}_{i, 50 \%}$ increases by almost $30 \%\left(\mathrm{CWC}_{i, 50 \%}\right.$ case compared to $\left.\mathrm{CWC}_{i}\right)$. Hence, if two different size distributions produce an identical Ze, CWC can be significantly different. In other words, Ze may differ significantly for the same CWC associated with two underlying different size distributions even without considering uncertainties in concentration measurements.

\section{Impact of graupel on retrieved CWCs}

Graupel are more spherical than pristine ice crystal shapes and aggregates. When approximating graupel particles as oblate spheroids in the T-matrix calculations, their density is close to solid ice density and their aspect ratio is close to 1. Hence, observations of graupel particles dominating the crystal populations are investigated within the entire dataset to estimate their impact on retrieved CWCs. A detection algorithm of virtually spherical particles has been applied to PIP image data to select events where graupel are observed. Most of these events are observed for $N_{\mathrm{T}}>2000 \mathrm{~L}^{-1}$, $\mathrm{CWC}>1 \mathrm{~g} \mathrm{~m}^{-3}$. For those events, retrieved $\overline{\mathrm{CWC}}$ also have relative errors larger than $100 \%$. Some events are also detected for $N_{\mathrm{T}}<2000 \mathrm{~L}^{-1}$, but with relative errors less than $30 \%$. Table 1 gives relative errors for graupel events only (bracketed bold numbers). It shows mean and median relative errors of retrieved $\overline{\mathrm{CWC}}$ s without corrections and with correction applied from Eqs. (9) to (11). The correction as a function of $N_{\mathrm{T}}$ (Eq. 9) has the largest impact on the relative errors (mean and median) for graupel events. Indeed, mean relative errors of retrieved $\overline{\mathrm{CWC}}$ s for all graupel events are $83 \%$ (without correction) and $16 \%$ (after $f\left(N_{\mathrm{T}}\right)$ correction). Likewise, the percentages for the median relative errors are 75 and $7 \%$, respectively, without and with correction. Note 

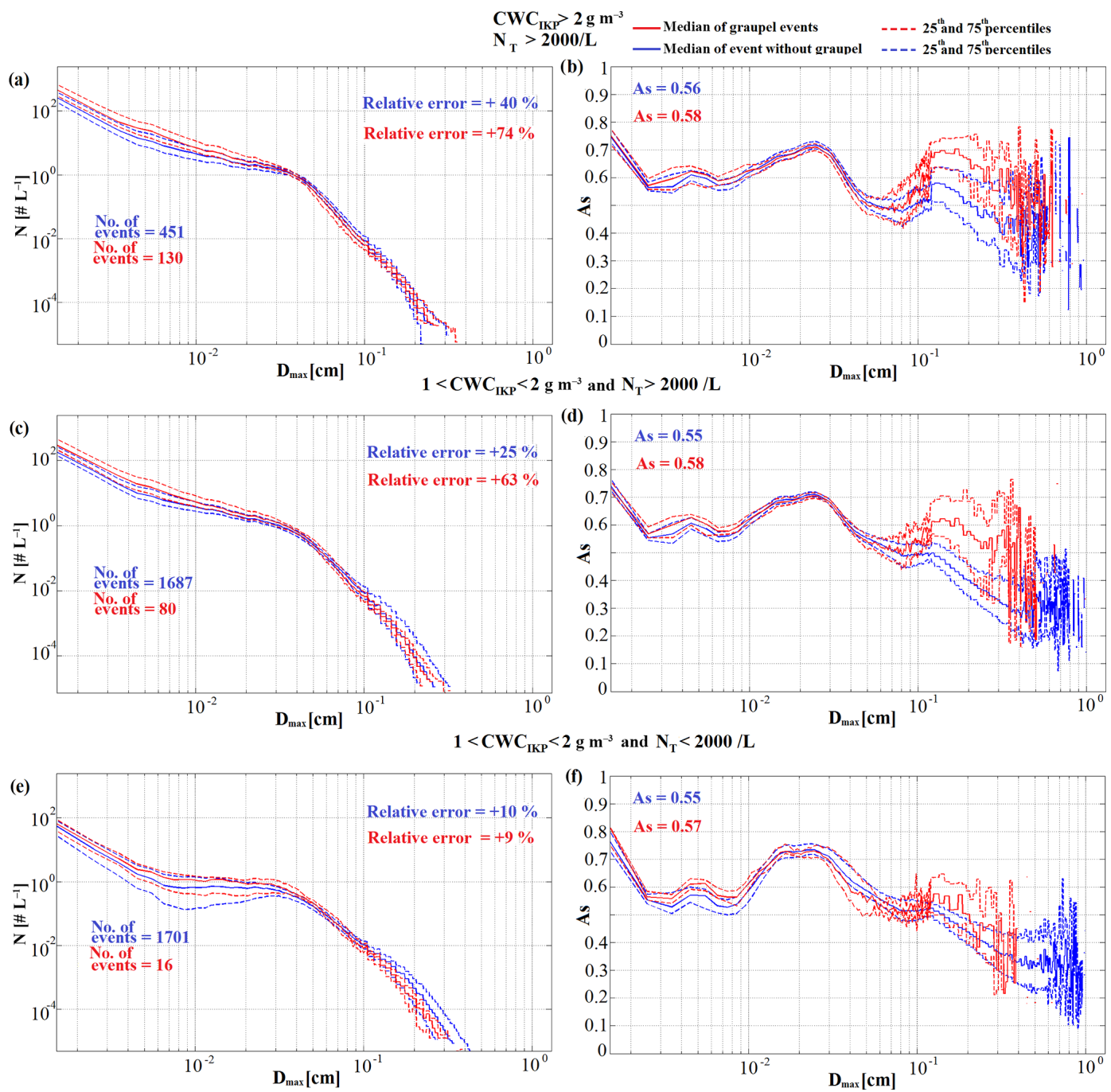

Figure 9. For three cloud categories discussed in Sect. 5, (a, c, e) show the number size distributions of ice crystals and (b, d, f) present the respective aspect ratio distributions of ice hydrometeors as a function of crystal size on the $x$ axis. Median distributions are indicated by a solid line and the 25th and 75th percentiles by dashed lines. The red curves are used for events where graupel are detected, whereas blue is used for events without graupel particles. In addition, median relative errors of retrieved uncorrected $\overline{\mathrm{CWC}}$, corresponding median aspect ratios, and number of observed events (for both graupel and non-graupel events) are added as numbers in the figures.

that corrections as functions of $\max \left(D_{\max }\right)$ and $T$ are less efficient in reducing mean and median relative errors of retrieved $\overline{\mathrm{CWC}}$ s for graupel events.

In the following, three different microphysical categories are distinguished in order to compare PSD and $\operatorname{As}\left(D_{\max }\right)$ of observed graupel events with respective non-graupel data:

1. $\mathrm{CWC}_{\mathrm{IKP}}>2 \mathrm{~g} \mathrm{~m}^{-3}$ and $N_{\mathrm{T}}>2000 \mathrm{~L}^{-1}$ (Fig. 9a and b),

2. $1<\mathrm{CWC}_{\mathrm{IKP}}<2 \mathrm{~g} \mathrm{~m}^{-3}$ and $N_{\mathrm{T}}>2000 \mathrm{~L}^{-1}$ (Fig. 9c and $\mathrm{d})$, and

3. $1<\mathrm{CWC}_{\mathrm{IKP}}<2 \mathrm{~g} \mathrm{~m}^{-3}$ and $N_{\mathrm{T}}<2000 \mathrm{~L}^{-1}$ (Fig. 9e and $\mathrm{f}$ )

Figure 9 shows median, 25th, and 75th percentiles of PSDs (Fig. 9a, c, and e) and size-dependent $\operatorname{As}\left(D_{\max }\right)$ (Fig. 9b, d, and f). Graupel and non-graupel events are shown as red and blue lines, respectively. From this figure, there is no evidence of significant differences between median PSDs with and without detection of graupel particles (three left figures). However, the median aspect ratio substantially changes for hydrometeors larger than $1 \mathrm{~mm}$, with increased $\operatorname{As}\left(D_{\max }\right)$ for the graupel particle events compared to non-graupel events. For all three graupel categories defined above, the number of observations with graupel particles are smaller than those without graupel particles. Indeed, for the event category where $\mathrm{CWC}_{\mathrm{IKP}}>2 \mathrm{~g} \mathrm{~m}^{-3}$ and $N_{\mathrm{T}}>2000 \mathrm{~L}^{-1}$ a total of 451 events without graupel particles and solely 130 events with graupel particles are detected, with median relative errors in uncorrected retrieved $\overline{\mathrm{CWC}}$ of +40 and $+74 \%$, respec- 
tively. For the event category with $1<\mathrm{CWC}_{\mathrm{IKP}} \leq 2 \mathrm{~g} \mathrm{~m}^{-3}$ and $N_{\mathrm{T}}>2000 \mathrm{~L}^{-1}$, there are 1687 and 80 graupel and nongraupel events, respectively, with median relative error of uncorrected retrieved $\overline{\mathrm{CWC}}$ of +25 and $+63 \%$, respectively. Finally, for the third category $\left(1<\mathrm{CWC}_{\mathrm{IKP}}<2 \mathrm{~g} \mathrm{~m}^{-3}\right.$ and $N_{\mathrm{T}}<2000 \mathrm{~L}^{-1}$ ) only 16 events are detected with graupel particles compared to 1701 events without graupel particles, with corresponding median relative errors of +10 and $+9 \%$, respectively. Graupel particles seem to have smaller impact on this third category as compared to two other categories. Most of the graupel events occur for high crystal number concentrations $\left(N_{\mathrm{T}}>2000 \mathrm{~L}^{-1}\right)$, thereby leading to higher median relative errors in uncorrected retrieved $\overline{\mathrm{CWC}}$ as compared to the non-graupel events.

\section{Discussion and conclusions}

The objective of the present study was to evaluate with direct CWC observations the CWC retrieval technique outlined in Fontaine et al. (2014), based on matching simulated radar reflectivity factors from PSD measurements with measured radar reflectivity factors at $94 \mathrm{GHz}$. Since mass-size relationships are considered to be unknown, the reflectivity simulations explore a wide range of possible solutions of $\left(\alpha_{i}, \beta_{i}\right)$, varying $\beta$ in the range of 1 to 3 . This produces a series of possible CWCs for a given data point, one for each value of $\beta$. From this series, the average value $\overline{\mathrm{CWC}}$ over all values of $\beta$ is calculated. On average it is found that the difference $\operatorname{CWC}(\beta=1)-\operatorname{CWC}(\beta=3)$ is approximately $64 \%$ of the average $\overline{\mathrm{CWC}}$. Of the Darwin data points, $77 \%$ meet the condition of $\operatorname{CWC}(\beta=3) \leq \mathrm{CWC}_{\mathrm{IKP}} \leq \mathrm{CWC}(\beta=1)$, which goes along with the relation $\mathrm{CWC}_{\mathrm{IKP}}=\overline{\mathrm{CWC}} \pm 32 \%$. However, the retrieved $\overline{\mathrm{CWC}}$ values are generally larger than $\mathrm{CWC}_{\text {IKP }}$ by about $16 \%$ (median value), which illustrates that the approximation of ice oblate spheroids tends to underestimate the backscattered energy of real reflectivity measurements of ice hydrometeors at $94 \mathrm{GHz}$, and a constant factor of 0.84 could be applied as a first-order correction of retrieved $\overline{\mathrm{CWC}}$.

One of the possible explanations is that the calculation of the average aspect ratio from 2-D images (Eqs. 5 and 6) which has been adopted as the flattening parameter utilized for the approximation of ice oblate spheroids might be somewhat too large. A way to investigate impact and calculation of axis ratio for ice oblate spheroids approximations would be to use $\operatorname{As}\left(D_{\max }\right)$ instead of $\overline{\mathrm{As}}$ (Eq. 5) in simulations of radar reflectivity factors.

This study also demonstrated that the total concentration of ice hydrometeors could be used as input for a correction algorithm that minimizes differences between $\overline{\mathrm{CWC}}$ and $\mathrm{CWC}_{\mathrm{IKP}}$ and that this parameter was the best of several parameters evaluated for this purpose. These differences, before correction, were found to increase with increasing ice concentration, with $\overline{\mathrm{CWC}}$ underestimating $\mathrm{CWC}_{\mathrm{IKP}}$ at low ice concentrations and overestimating $\mathrm{CWC}_{\mathrm{IKP}}$ at high concentrations.

Another attempt of explanation is the uncertainty of measured total crystal concentrations, which could partly explain large relative errors at high concentrations. Indeed, for very high concentrations we find a higher relative error of about $+50 \%$ as compared to IKP measurements. However, according to the results of Sect. 4 of this study, an uncertainty of $50 \%$ in ice crystals concentrations can solely explain $30 \%$ of the relative errors. Likewise, concentration errors related to large crystal shattering could not explain more than $35 \%$ of the relative errors at very high concentrations of ice hydrometeors. However, this cannot explain the negative relative errors for low ice crystal concentrations. Also, at very low ice crystals concentrations oblate spheroids approximation of crystals could be not sufficiently adapted, since for low concentrations real shapes of ice hydrometeors might be even more important due to the lack of any averaging process over all possible shapes and possible orientations as should be more likely the case for higher concentrations.

Moreover, graupel particles are found to substantially affect the relative errors in retrieved $\overline{\mathrm{CWC}}$ s in high total concentration situations as compared to moderate total crystal concentration situations with graupel. In the latter observed conditions, graupel may have been less numerous and their impact on the aspect ratio of ice hydrometeors larger than $1 \mathrm{~mm}$ becomes less important than at higher concentrations $\left(N_{\mathrm{T}}>2000\right)$. Despite the fact that most graupel events are found during high crystal concentration conditions, the correction function $f\left(N_{\mathrm{T}}\right)$ appears to be very efficient in reducing the relative error in retrieved $\overline{\mathrm{CWC}}$ when graupels are detected. Since the suggested $f\left(N_{\mathrm{T}}\right)$ correction has been established for the entire dataset and is not exclusively designed for the graupel event correction of retrieved $\overline{\mathrm{CWC}}$, median relative errors of $f\left(N_{\mathrm{T}}\right)$ corrected $\overline{\mathrm{CWC}}$ of all graupel data are of the order of $7 \%$ compared to $-1 \%$ for the entire dataset (see Table 1).

This study does not focus on the mass-size relationship directly, but it is clear that the coefficients of the $m(D)$ relationship, and particularly its exponent, considerably impact the simulation of radar reflectivity factors on the one hand and CWC calculation on the other hand. In this context, we recall that Fontaine et al. (2014) obtain different CWCs for one and the same radar reflectivity factor, which is also valid reciprocally, where one and the same CWC is related to a range of radar reflectivity factors, thereby varying the $\beta$ exponent and corresponding prefactors $\alpha$ in the $\mathbf{T}$-matrix simulations of the radar reflectivity factors. Hence, getting large differences between calculated CWC (related to radar reflectivity simulations) and measured CWC from IKP-2 does not mean that the oblate spheroid approximation for $\mathrm{Ze}$ is wrong, but the difference stems primarily from the choice of $\beta$ (and respective $\alpha$ ) of the mass-size relationship. We are aware that a single $m(D)$ power law is not sufficient to assimilate all the complexity of the mass of ice hydrometeors. The main goal 
of this paper is to evaluate the Fontaine et al. (2014) method of calculating an average CWC from all possible solutions for $(\alpha, \beta)$ without a priori assumption. The method has been already used in further studies: Drigeard et al. (2015) and Alcoba et al. (2015). Finally, the method allows constraining the effective density of ice hydrometeors and also the simulation of radar reflectivity factors at different frequencies: 94 , 9.4 and $5.5 \mathrm{GHz}$. The method will be used in the near future to derive mass-size relationships for different size ranges of the ice hydrometeors' size spectrum.

Data availability. No data sets were used in this article.

Competing interests. The authors declare that they have no conflict of interest.

Acknowledgements. The research leading to these results has received funding from (i) the European Union's Seventh Framework Program in research, technological development and demonstration under grant agreement no. ACP2-GA-2012-314314, (ii) the European Aviation Safety Agency (EASA) Research Program under service contract no. EASA.2013.FC27, and (iii) the Federal Aviation Administration (FAA), Aviation Research Division, and Aviation Weather Division, under agreement CON-I-1301 with the Centre National de la Recherche Scientifique. Funding to support the Darwin flight project was also provided by the NASA Aviation Safety Program, the Boeing Co., and Transport Canada. Additional support was also provided by Airbus SAS Operations, Science Engineering Associates, the Bureau of Meteorology, Environment Canada, the National Research Council of Canada, and the universities of Utah and Illinois. The authors thank the SAFIRE facility for the scientific airborne operations. SAFIRE (http://www.safire.fr) is a joint facility of CNRS, Météo-France, and CNES dedicated to flying research aircraft.

Edited by: G. Vulpiani

Reviewed by: two anonymous referees

\section{References}

Alcoba, M., Gosset, M., Kacou, M., Cazenave, F., and Fontaine, E.: Characterization of Hydrometeors in Sahelian Convective Systems with an Xband radar and comparison with in situ measurements. Part 2: a simple bright band method to infer the density of icy hydrometeors, J. Appl. Meteor. Climatol., https://doi.org/10.1175/JAMC-D-15-0014.1, 2015.

Brown, P. R. A. and Francis, P. N.: Improved Measurements of the Ice Water Content in Cirrus Using a Total-Water Probe, J. Atmos. Ocean. Technol., 12, 410-414, https://doi.org/10.1175/15200426(1995)012<0410:IMOTIW>2.0.CO;2, 1995.

Davison, C., Mac Leod, J. D., Strapp, J. W., and Buttsworth, D. R.: "Isokinetic Total Water Content Probe in a Naturally Aspirating Configuration: Initial Aerodynamic Design and Testing", 46th AIAA Aerospace Sciences Meeting and Exhibit, 2008.
Davison, C. R., Strapp, J. W., Lilie, L., Ratvasky, T. P., and Dumont, C.: Isokinetic TWC Evaporator Probe: Calculations and Systemic Error Analysis, 8th AIAA Atmospheric and Space Environments Conference, June 17, 2016, Washington, DC, AIAA 2016-4060, 2016.

Dezitter, F., Grandin, A., Brenguier, J.-L., Hervy, F., Schlager, H., Villedieu, P., and Zalamansky, G.: "HAIC - High Altitude Ice Crystals", in: 5th AIAA Atmospheric and Space Environments Conference, American Institute of Aeronautics and Astronautics, https://doi.org/10.2514/6.2013-2674, 2013.

Draine, B. T. and Flatau, P. J.: Discrete-dipole approximation for scattering calculations, J. Opt. Soc. Am. A, 11, 1491-1499, https://doi.org/10.1364/JOSAA.11.001491, 1994.

Drigeard, E., Fontaine, E., Wobrock, W., Schwarzenböck, A., Duroure, C., Williams, E.R., Russell, B., Protat, A., Delanoë, J., Cazenave, F., and Gosset, M.: A Comparison of Airborne In Situ Cloud Microphysical Measurement with Ground-Based C-Band Radar Observations in Deep Stratiform Regions of African Squall Lines, J. Appl. Meteor. Climatol., 54, 2461-2477, https://doi.org/10.1175/JAMC-D-14-0262.1, 2015.

Field, P. R., Heymsfield, A. J., and Bansemer, A.: Shattering and Particle Interarrival Times Measured by Optical Array Probes in Ice Clouds, J. Atmos. Ocean. Technol., 23, 1357-1371, https://doi.org/10.1175/JTECH1922.1, 2006.

Fontaine, E.: Masse des Cristaux de Glace et Facteurs de Réflectivité Radar dans les Systèmes de Nuages Convectifs de Moyenne Echelle Formés dans les Tropiques et la Région de la Mer Méditerranée, Université Blaise Pascal, PhD thesis, 2014.

Fontaine, E., Schwarzenboeck, A., Delanoë, J., Wobrock, W., Leroy, D., Dupuy, R., Gourbeyre, C., and Protat, A.: Constraining mass-diameter relations from hydrometeor images and cloud radar reflectivities in tropical continental and oceanic convective anvils, Atmos. Chem. Phys., 14, 11367-11392, https://doi.org/10.5194/acp-14-11367-2014, 2014.

Heymsfield, A. J., Schmitt, C., and Bansemer, A.: Ice Cloud Particle Size Distributions and Pressure-Dependent Terminal Velocities from In Situ Observations at Temperatures from $0^{\circ}$ to $-86^{\circ} \mathrm{C}$, J. Atmos. Sci., 70, 4123-4154, https://doi.org/10.1175/JAS-D-120124.1, 2013.

Hogan, R. J., Mittermaier, M. P., and Illingworth, A. J.: The Retrieval of Ice Water Content from Radar Reflectivity Factor and Temperature and Its Use in Evaluating a Mesoscale Model, J. Appl. Meteor. Climatol., 45, 301-317, https://doi.org/10.1175/JAM2340.1, 2006.

Hogan, R. J., Tian, L., Brown, P. R. A., Westbrook, C. D., Heymsfield, A. J., and Eastment, J. D.: Radar Scattering from Ice Aggregates Using the Horizontally Aligned Oblate Spheroid Approximation, J. Appl. Meteorol. Climatol., 51, 655-671, https://doi.org/10.1175/JAMC-D-11-074.1, 2011.

Jackson, R. C., McFarquhar, G. M., Stith, J., Beals, M., Shaw, R. A., Jensen, J., Fugal, J., and Korolev, A.: An Assessment of the Impact of Antishattering Tips and Artifact Removal Techniques on Cloud Ice Size Distributions Measured by the 2D Cloud Probe, J. Atmos. Ocean. Technol., 31, 2567-2590, https://doi.org/10.1175/JTECH-D-13-00239.1, 2014.

Korolev, A. and Field, P. R.: Assessment of the performance of the inter-arrival time algorithm to identify ice shattering artifacts in cloud particle probe measurements, Atmos. Meas. Tech., 8, 761777, https://doi.org/10.5194/amt-8-761-2015, 2015. 
Korolev, A. and Sussman, B.: A Technique for Habit Classification of Cloud Particles, J. Atmos. Ocean. Technol., 17, 1048-1057, https://doi.org/10.1175/15200426(2000)017<1048:ATFHCO>2.0.CO;2, 2000.

Korolev, A. and Isaac, G. A.: Shattering during Sampling by OAPs and HVPS, Part I: Snow Particles, J. Atmos. Ocean. Technol., 22, 528-542, https://doi.org/10.1175/JTECH1720.1, 2005.

Korolev, A.: Reconstruction of the Sizes of Spherical Particles from Their Shadow Images, Part I: Theoretical Considerations, J. Atmos. Ocean. Technol., 24, 376-389, https://doi.org/10.1175/JTECH1980.1, 2007.

Lawson, R. P.: Effects of ice particles shattering on the 2D-S probe, Atmos. Meas. Tech., 4, 1361-1381, https://doi.org/10.5194/amt4-1361-2011, 2011.

Leroy, D., Fontaine, E., Schwarzenboeck, A., and Strapp, J. W.: Ice Crystal Sizes in High Ice Water Content Clouds, Part I: On the Computation of Median Mass Diameter from In Situ Measurements, J. Atmos. Ocean. Technol., 33, 2461-2476, https://doi.org/10.1175/JTECH-D-15-0151.1, 2016.

Leroy, D., Fontaine, E., Schwarzenboeck, A., Strapp, J. W., Korolev, A., McFarquhar, G., Dupuy, R., Gourbeyre, C., Lilie, L., Protat, A., Delanoe, J., Dezitter, F., and Grandin, A.: Ice Crystal Sizes in High Ice Water Content Clouds, Part II: Statistics of Mass Diameter Percentiles in Tropical Convection Observed during the HAIC/HIWC Project, J. Atmos. Ocean. Technol., 34, 117-136, https://doi.org/10.1175/JTECH-D-15-0246.1, 2017.

Li, J.-L., Jiang, J. H., Waliser, D. E., and Tompkins, A. M.: Assessing consistency between EOS MLS and ECMWF analyzed and forecast estimates of cloud ice, Geophys. Res. Lett., 34, L08701, https://doi.org/10.1029/2006GL029022, 2007.

Li, J.-L., Waliser, D. E., Jiang, J. H., Wu, D. L., Read, W., Waters, J. W., Tompkins, A. M., Donner, L. J., Chern, J.-D., Tao, W.-K., Atlas, R., Gu, Y., Liou, K. N., Del Genio, A., Khairoutdinov, M., and Gettelman, A.: Comparisons of EOS MLS cloud ice measurements with ECMWF analyses and GCM simulations: Initial results, Geophys. Res. Lett., 32, L18710, https://doi.org/10.1029/2005GL023788, 2005.

Liu, G.: A Database of Microwave Single-Scattering Properties for Nonspherical Ice Particles, B. Am. Meteorol. Soc., 89, 15631570, https://doi.org/10.1175/2008BAMS2486.1, 2008.

Locatelli, J. D. and Hobbs, P. V.: Fall speeds and masses of solid precipitation particles, J. Geophys. Res., 79, 2185-2197, https://doi.org/10.1029/JC079i015p02185, 1974.

Mason, J. G., Strapp, J. W., and Chow, P.: The ice particle threat to engines in flight, 44th AIAA Aerospace Sciences Meeting, Reno, Nevada, 9-12 January 2006, AIAA-2006-206, 2006.

Maxwell Garnet, J. C.: Colours in Metal Glasses and in Metallic Films, Philos. T. R. Soc., 203, 385-420, https://doi.org/10.1098/rsta.1904.0024, 1904.
Mioche, G.: Validation dess produits d'inversion des observations CALIPSO/CloudSat pour la caractérisation des propriétés optiques et microphysiques des nuages de glace et en phase mixte, Université Blaise Pascal, Clermont-Ferrand 2, PhD thesis, 2010.

Mishchenko, M. I., Travis, L. D., and Mackowski, D. W.: Tmatrix computations of light scattering by nonspherical particles: A review, J. Quant. Spectrosc. Ra., 55, 535-575, https://doi.org/10.1016/0022-4073(96)00002-7, 1996.

Protat, A., Delanoë, J., Bouniol, D., Heymsfield, A. J., Bansemer, A., and Brown, P.: Evaluation of Ice Water Content Retrievals from Cloud Radar Reflectivity and Temperature Using a Large Airborne In Situ Microphysical Database, J. Appl. Meteorol. Climatol., 46, 557-572, https://doi.org/10.1175/JAM2488.1, 2007.

Protat, A., Bouniol, D., Delanoë, J., O'Connor, E., May, P. T., Plana-Fattori, A., Hasson, A., Görsdorf, U., and Heymsfield, A. J.: Assessment of Cloudsat Reflectivity Measurements and Ice Cloud Properties Using Ground-Based and Airborne Cloud Radar Observations, J. Atmos. Ocean. Technol., 26, 1717-1741, https://doi.org/10.1175/2009JTECHA1246.1, 2009.

Protat, A., Delanoë, J., Strapp, J. W., Fontaine, E., Leroy, D., Schwarzenboeck, A., Lilie, L., Davison, C., Dezitter, F., Grandin, A., and Weber, M.: The Measured Relationship between Ice Water Content and Cloud Radar Reflectivity in Tropical Convective Clouds, J. Appl. Meteorol. Climatol., 55, 1707-1729, https://doi.org/10.1175/JAMC-D-15-0248.1, 2016.

Roca, R., Brogniez, H., Chambon, P., Chomette, O., Cloché, S., Gosset, M. E., Mahfouf, J., Raberanto, P., and Viltard, N.: The Megha-Tropiques mission: a review after three years in orbit, Front. Earth Sci., 3, 17, https://doi.org/10.3389/feart.2015.00017, 2015.

Stephens, G. L., Vane, D. G., Boain, R. J., Mace, G. G., Sassen, K., Wang, Z., Illingworth, A. J., O’Connor, E. J., Rossow, W. B., Durden, S. L., Miller, S. D., Austin, R. T., Benedetti, A., Mitrescu, C., and CloudSat Science Team: THE CLOUDSAT MISSION AND THE A-TRAIN, B. Am. Meteorol. Soc., 83, 1771-1790, https://doi.org/10.1175/BAMS-83-12-1771, 2002.

Strapp, J. W., Isaac, G. A., Korolev, A., Ratvasky, T., Potts, R., May, P., Protat, A., Minnis, P., Ackerman, A., Fridlind, A., Haggerty, J., and Riley, J.: The High Ice Water Content (HIWC) Study of deep convective clouds: Science and technical plan, FAA Rep. DOT/FAA/TC-14/31, 105 pp., available at: http://www.tc.faa. gov/its/worldpac/techrpt/tc14-31.pdf (last access: 12 June 2017), 2016.

Strapp, J. W., Lilie, L., Ratvasky, T. P., Davison, C. R., and Dumont, C.: Isokinetic TWC Evaporator Probe Development and Performance Testing for the HAIC-HIWC Darwin 2014 and Cayenne 2015 Field Campaigns, 2016, 8th AIAA Atmospheric and Space Environments Conference, 17 June 2016, Washington, DC, (article number pending), 2016. 